\title{
The symptom of depression in schizophrenia and its management
}

\author{
Ciaran Mulholland \& Stephen Cooper
}

Depression is a frequently occurring symptom in schizophrenia. While today it is often underrecognised and under-treated, historically such symptoms were the focus of much attention. Affective symptoms were used by Kraepelin as an important criterion with which to separate dementia praecox from manic-depressive illness. Kraepelin also recognised the importance of depression as a symptom in schizophrenia and identified several depressive subtypes of the illness. Mayer-Gross emphasised the despair that often occurs as a psychological reaction to acute psychotic episodes and Bleuler considered depression to be one of the core symptoms of schizophrenia.

Depressive symptoms in schizophrenia are important not only because they contribute significantly to the suffering caused by the illness, whether 'positive' psychotic symptoms are active or quiescent, but also because they exacerbate deficits in psychosocial functioning and commonly precede attempted and completed suicide. It is important to define and clinically assess such symptoms accurately as there is now increasing evidence that they can be treated successfully.

\section{Differential diagnosis of depression in schizophrenia}

There are a number of important differential diagnoses of depressive symptoms in schizophrenia. We can assume that depression and schizophrenia are not simply two independent illnesses occurring together by chance, on the basis of the epidemiology of each illness. Differential diagnoses to consider include schizoaffective disorder, organic conditions and the negative symptoms of schizophrenia. It has been argued by some that depression may in some way be 'caused' by antipsychotic medication and this issue will be discussed in detail. Depression may also be an understandable psychological reaction to schizophrenia. When all of these possibilities have been excluded, there is evidence that depression is perhaps most often an integral part of the schizophrenic process itself.

\section{Schizoaffective disorder}

Differentiating schizophrenia with clinically significant depressive symptoms from schizoaffective disorder is not always easy. Clearly, the exact dividing line between the two conditions is a conceptual one. Operationalised criteria such as ICD-10 (World Health Orgnization, 1992) allow us to make such a differentiation on a day-to-day basis (see Boxes 1 and 2) and will dictate treatment options to an extent. The nature and treatment of schizoaffective disorder falls outside the remit of this review.

\section{Adjustment reactions}

Schizophrenia carries a heavy psychological burden and it is not surprising that disappointment reactions to life's vicissitudes occur commonly. Acute reactions, lasting less than two weeks, are self-limiting and require supportive treatment or manipulation of the environment only. Often, a clear precipitating cause can be identified.

Ciaran Mulholland is a consultant psychiatrist at Holywel Hospital, Antrim, Northern Ireland. Stephen Cooper is a Senior Lecturer and Head of the Department of Mental Health, The Queen's University of Belfast, Northern Ireland (Whitla Medical Building, 97 Lisburn Road, Belfast BT9 7BL; tel: 01232 3357910; fax: 01232 324543; e-mail: s.cooper@qub.ac.uk). They have research interests in the epidemiology, causes and neurochemical basis of depression in schizophrenia. 
There are some patients who can be characterised as suffering from a demoralisation syndrome or a chronic disappointment reaction. Differentiating such a syndrome from depression is not always easy. It is characterised by hopelessness and helplessness, with a lack of confidence and feelings of incompetence. The appropriate treatment is supportive or rehabilitative rather than pharmacological.

Clearly, a reactive process cannot explain the majority of cases of depression in schizophrenia. If such a process, dependent to an extent on the return of insight, is at work, then depressive symptoms should become more common as acute psychotic symptoms respond to treatment. The opposite appears to be the case, however, with depressive symptoms more often resolving as positive symptoms resolve.

\section{Organic factors}

Depression-like syndromes can occur secondary to a range of medical conditions (Table 1). Neoplasms, anaemias, infections, neurological disorders and endocrine disorders can induce psychological symptoms directly in the person with schizophrenia, or depressive symptoms may occur as a reaction to illness. A myocardial infarction, for example, may present as agitation and emotional distress in someone with schizophrenia as there can be an altered pain threshold and inability to describe symptoms adequately. The medication used to treat medical disorders may also cause depressive symptoms as a side-effect. Antihypertensives, corticosteroids, anticonvulsants and L-dopa, among

Box 1. ICD-10 diagnostic guidelines for post-schizophrenic depression

The patient has met general criteria for schizophrenia within past 12 months

Some schizophrenic symptoms are still present, but no longer dominate the clinical picture (symptoms may be 'positive' or 'negative', though the latter are more common)

The depressive symptoms are prominent and distressing, fulfilling at least the criteria for a depressive episode, and have been present for at least two weeks (they are rarely sufficiently severe or extensive to meet criteria for a severe depressive episode) others, may give rise to problems. The medical history of any patient presenting with depressive symptoms should thus be carefully scrutinised. In addition, the entire range of medication that they receive, not just their psychotropic medication, and any recent changes in medication, should be considered as possible aetiological factors.

Substance misuse is also a common cause of depressive symptoms, either as a direct effect of the substance concerned or as a withdrawal phenomenon. Alcohol is undoubtedly the most common substance causing problems. Arguably, cannabis can cause depressive symptoms with long-term use, and nicotine and caffeine may cause dysphoria upon withdrawal. Cocaine, less commonly used and more often associated with manic symptoms, can cause depression upon withdrawal. The same applies to other psychostimulants (Table 1).

\section{Differentiating depressive from negative symptoms}

The 'negative' features of schizophrenia have many clinical similarities to the syndrome of depression. Lack of energy, anhedonia and social withdrawal may cause particular problems when attempting to differentiate between the two syndromes. Observed sadness is an unreliable indicator of depression in schizophrenia. Prominent subjectively low mood, suggesting depression, and prominent blunting of affect, suggesting negative symptoms, are the two features which are most helpful in differentiating the two syndromes (Siris, 1994). An emphasis on

Box 2. ICD-10 diagnostic guidelines for schizoaffective disorder - depressed type

Both definite schizophrenic and definite affective symptoms are prominent simultaneously, or within a few days of each other, within the same episode of illness

As a consequence of this, the episode of illness does not meet criteria for either schizophrenia or for a depressive or manic episode

There must be prominent depression accompanied by at least two characteristic depressive symptoms or associated behavioural abnormalities as for a depressive episode

At least one and preferably two typically schizophrenic symptoms, as specified for schizophrenia, must be present 
Table 1. Main differential diagnoses of depressive symptoms in schizophrenia

\begin{tabular}{|c|c|c|}
\hline Diagnosis & Comment & Intervention \\
\hline \multicolumn{3}{|l|}{ Organic factors } \\
\hline Medical conditions & $\begin{array}{l}\text { Anaemias, neoplasms, infections, } \\
\text { neurological disorders etc. }\end{array}$ & Treat underlying cause \\
\hline Drug side-effects & $\begin{array}{l}\text { Beta-blockers, calcium antagonists, } \\
\text { hypnotics, indomethacin, sulphonomides, } \\
\text { corticosteroids, etc. }\end{array}$ & $\begin{array}{l}\text { Treat underlying cause (i.e. } \\
\text { stop medication if possible) }\end{array}$ \\
\hline Drug withdrawal & From benzodiazepine, for example & Controlled withdrawal \\
\hline Misuded drugs & $\begin{array}{l}\text { Direct effect (e.g. alcohol) or } \\
\text { withdrawal effect (e.g. cocaine) }\end{array}$ & $\begin{array}{l}\text { Controlled withdrawal and } \\
\text { possible referral to addiction } \\
\text { service }\end{array}$ \\
\hline Negative symptoms & $\begin{array}{l}\text { Primary negative symptoms can be } \\
\text { differentiated from depressive } \\
\text { symptoms (see text) }\end{array}$ & Consider atypicals \\
\hline Schizoaffective disorder & $\begin{array}{l}\text { Establish differential diagnosis } \\
\text { (see Boxes } 1 \text { and } 2 \text { ) }\end{array}$ & $\begin{array}{l}\text { Appropriate treatment for } \\
\text { schizoaffective disorder }\end{array}$ \\
\hline \multicolumn{3}{|l|}{ Adjustment disorders } \\
\hline Acute & Duration less than two weeks & Psychosocial support \\
\hline $\begin{array}{l}\text { Chronic ('demoralization } \\
\text { syndrome') }\end{array}$ & Prolonged duration & $\begin{array}{l}\text { Psychosocial support } \\
\text { Consider antidepressant }\end{array}$ \\
\hline
\end{tabular}

the patient's view of him- or herself may thus be a useful approach in detecting important aspects of depressive symptomatology in schizophrenia. Other symptoms that help to establish the diagnosis of depression include some of the main psychological features that occur in primary depressive illness, such as hopelessness, helplessness, worthlessness, guilt, anxiety and suicidal thinking. In schizophrenia, the biological features of the depressive syndrome, such as insomnia and retardation, are not always present - and if they are present, they can be more difficult to disentangle from negative symptoms and can be an intrinsic part of the illness separate from any superimposed depressive syndrome.

\section{The role of antipsychotic medication}

The role of antipsychotic medication in the aetiology of depressive symptoms in schizophrenia is somewhat controversial. There have been three principal proposed roles (Table 2).

Thirty years ago, it was proposed that antipsychotics acted directly causing 'pharmacogenic depression' (De Alarcon \& Carney, 1969). There is a possible theoretical explanation for this as antipsychotics act primarily on dopaminergic pathways and dopamine plays a major role in reward and pleasure mechanisms. An alternative hypothesis proposed that akinesia, an extrapyramidal side-effect of antipsychotic medication, and not necessarily accompanied by other symptoms, such as tremor, can mimic depression. This phenomenon has been termed 'akinetic depression' (Van Putten \& May, 1978). Patients behave 'as if their starter motor is broken' and display anergia and akinesia, sometimes with accompanying low mood. Van Putten \& May considered this to be a new symptom of extrapyramidal disorder, not part of Parkinsonian syndrome. Whether it can be reliably differentiated from Parkinsonian syndrome and is in fact a separate clinical entity remains open to question.

Although some observations have supported these hypotheses, the weight of evidence has been against, suggesting that antipsychotics are responsible for relatively few cases of depression in schizophrenia. Depression can occur in antipsychotic-free patients with schizophrenia (Johnson, 1981a), the prevalence of significant depression falls when antipsychotic treatment is commenced (Hirsch et al, 1989) and when antipsychotics are discontinued there is an increase in the percentage of patients requiring antidepressants (Hirsch et al, 1973). Several studies have shown no difference between depressed and non-depressed patients with schizophrenia in the dosage of antipsychotic medication received. 
Table 2. Antipsychotic medication and depressive symptoms in schizophrenia

\begin{tabular}{|c|c|c|c|}
\hline Proposed term & Proposed mechanism & Evidence for hypothesis & Intervention \\
\hline $\begin{array}{l}\text { 'Pharmacogenic' } \\
\text { depression }\end{array}$ & $\begin{array}{l}\text { Antipsychotics cause depression by } \\
\text { a direct effect (?dopaminergic) }\end{array}$ & Very weak & \\
\hline $\begin{array}{l}\text { 'Akinetic' } \\
\text { depression }\end{array}$ & $\begin{array}{l}\text { Antipsychotics produce extra- } \\
\text { pyramidal side-effects such as } \\
\text { bradykinesia and loss of } \\
\text { spontaneity, mimicking depression } \\
\text { (clinical phenocopy of depression) } \\
\text { Low mood can also occur } \\
\text { secondary to akinesia }\end{array}$ & $\begin{array}{l}\text { Possibly explains } 10-15 \% \\
\text { cases of 'depression' in } \\
\text { schizophrenia }\end{array}$ & $\begin{array}{l}\text { Reduce antipsychotic } \\
\text { Anticholinergic } \\
\text { medication } \\
\text { Consider atypical } \\
\text { antipsychotics }\end{array}$ \\
\hline $\begin{array}{l}\text { Antipsychotic- } \\
\text { induced } \\
\text { dysphoria }\end{array}$ & $\begin{array}{l}\text { Dysphoria with or without motor } \\
\text { features of akathisia. } \\
\text { May presentlike (agitated) } \\
\text { depression }\end{array}$ & $\begin{array}{l}\text { Chronic akathisia } \\
\text { presents in } 25 \% \text { of } \\
\text { patients } \\
\text { Proportion with significant } \\
\text { dysphoria unknown }\end{array}$ & $\begin{array}{l}\text { Anticholinergic drugs } \\
\text { (but less useful than in } \\
\text { akinesia } \\
\text { Benzodiazepines } \\
\text { Beta-blockers } \\
\text { Reduce antipsychotic dose } \\
\text { Consider atypical drug }\end{array}$ \\
\hline
\end{tabular}

Johnson (1981b) estimated that 'akinetic depression' accounts for $10-15 \%$ of depressive-type symptoms. It is difficult to know how accurate this claim is, but akinetic depression should always be considered as a possibility and anticholinergics as a treatment option. Depressive symptoms are as common in patients on anticholinergics as in those who are not, and anticholinergics are not an effective treatment for depressive symptoms (Johnson, 1981a).

More recently, attention has focused on the concept of antipsychotic-induced dysphoria. One study in normal volunteers (King et al, 1995) demonstrated that dysphoria often occurs in the absence of motor restlessness and can thus be underdiagnosed. It is possible that some patients with schizophrenia presenting with depressive symptoms may in fact be troubled by antipsychoticinduced dysphoria, without the associated motor aspects of akathisia that make the diagnosis more obvious. If present, dysphoria/akathisia is not a trivial side-effect and has even been associated with suicide (Drake \& Ehrlich, 1985).

\section{Depression as a core symptom of schizophrenia}

Although the above factors must always be considered, it is probably the case that the majority of patients with schizophrenia who also complain of significant depressive symptoms have these symptoms as an aspect of the illness process itself. Table 3 summarises the situations in which this occurs and the main approaches to management for these.

\section{Depression as a prodromal syndrome}

Depressive symptoms are common in the prodromal period prior to acute psychotic episodes. Herz \& Melville (1980) found that the symptoms most frequently mentioned by patients and their families were:

"symptoms of dysphoria that non-psychotic individuals experience under stress, such as eating less, having trouble concentrating, having trouble sleeping, depression and seeing friends less".

Indeed, depression, as described above, was described by $60 \%$ of patients and more than $75 \%$ of their relatives. Johnson et al's (1983) findings were less dramatic, with $20 \%$ of their cohort experiencing more prominent affective symptoms prior to relapse. The emergence of affective symptoms may represent a psychological reaction to impending relapse, may reflect an underlying biological process mediating both these symptoms and positive psychotic symptoms, or may be an epiphenomenon. In any event, newly emerging affective symptoms are a useful early warning sign of impending relapse.

\section{Depressive symptoms during acute episodes}

Depressive symptoms are most frequently associated with the acute phase of the illness. Such symptoms are most prevalent before medication is commenced 
Table 3. Depressive symptoms and the time-course of schizophrenia

\begin{tabular}{|c|c|c|c|}
\hline Stage & Relationship to acute episodes & $\begin{array}{l}\text { Estimated } \\
\text { prevalence }\end{array}$ & Treatment \\
\hline $\begin{array}{l}\text { Depression as a } \\
\text { prodromal } \\
\text { symptom }\end{array}$ & Sign of impending relapse & $50 \%$ & $\begin{array}{l}\text { Increase psychosocial } \\
\text { support } \\
\text { Do not decrease anti- } \\
\text { psychotics prematurely } \\
\text { Increase may be required }\end{array}$ \\
\hline $\begin{array}{l}\text { Depressive symtoms } \\
\text { as prominent } \\
\text { component of acute } \\
\text { episode }\end{array}$ & $\begin{array}{l}\text { Clearly present during acute episode } \\
\text { (differentiate from schizoaffective } \\
\text { disorder) } \\
\text { 'Revealed depression' - present during } \\
\text { acute episode but only revealed as } \\
\text { positive symptoms respond to } \\
\text { treatment }\end{array}$ & $22-80 \%$ & $\begin{array}{l}\text { Requires effective anti- } \\
\text { psychotic drug treatment } \\
\text { initially } \\
\text { Consider atypical anti- } \\
\text { psychotics } \\
\text { Require careful clinical } \\
\text { follow-up as risk of suicide }\end{array}$ \\
\hline $\begin{array}{l}\text { Early post-psychotic } \\
\text { depression (first } \\
\text { six months after } \\
\text { acute episode) }\end{array}$ & $\begin{array}{l}\text { Depressive symptoms resolve more } \\
\text { slowly than other symtoms of } \\
\text { acute episode } \\
\text { Depressive symptoms develop as } \\
\text { acute episode resolves }\end{array}$ & $25 \%$ & $\begin{array}{l}\text { (Below assumes other } \\
\text { possible causes eliminated) } \\
\text { Require to continue } \\
\text { adequate antipsychotic } \\
\text { treatment } \\
\text { Consider an atypical anti- } \\
\text { psychotic } \\
\text { If severe, may need an } \\
\text { antidepressant }\end{array}$ \\
\hline $\begin{array}{l}\text { Late post-psychotic } \\
\text { depression (more } \\
\text { than six months after } \\
\text { acute episode) }\end{array}$ & $\begin{array}{l}\text { Depressive symptoms develop } \\
\text { in aftermath of acute episode } \\
\text { or persist for more than six } \\
\text { months after acute episode, i.e. } \\
\text { course of depressive symptoms } \\
\text { does not correlate with course } \\
\text { of acute symptoms }\end{array}$ & $\begin{array}{l}13-33 \% \\
\text { (in-patients) }\end{array}$ & $\begin{array}{l}\text { An antidepressant should } \\
\text { be considered (SSRI first- } \\
\text { line) } \\
\text { Change of antipsychotic } \\
\text { may help a few patients } \\
\text { If no improvement, then } \\
\text { consider clozapine }\end{array}$ \\
\hline
\end{tabular}

SSRI, selective serotonin reuptake inhibitor.

(Knights \& Hirsch, 1981) and occur in more than half of first-episode or drug-free patients (Johnson, 1981a). The prevalence of depressive symptoms falls dramatically during the course of an admission for an acute relapse, and occurs in approximately $25 \%$ of patients during the six months following discharge. The close association between depressive symptoms and acute episodes adds weight to the hypotheses that such symptoms are a core feature of schizophrenia and suggests that depressive symptoms and more typically schizophrenic symptoms may share common pathophysiological processes.

\section{Depressive symptoms in chronic schizophrenia}

Lower rates of depressive symptoms are seen in the chronic phase of the illness with a range of $4-25 \%$ and an estimated mean of 15\% (Leff, 1990). Most of the reported studies on chronic patients do not define the clinical stability or otherwise of the patients involved. In one study (Pogue-Geile, 1989), only patients who were clinically stable (not hospitalised in the previous six months, no medication changes in previous six weeks and judged by their clinician to be stable) and who were living in the community were assessed, and 9\% were found to be currently depressed. Persistent positive symptoms in the chronic phase of the illness may lead to distress, demoralisation and depression.

\section{Post-psychotic depression}

The occurrence of depressive symptoms during the chronic phase of schizophrenia has been given close attention in recent years. The terms 'post-psychotic 
depression', 'post-schizophrenic depression' and 'secondary depression' have been used to describe this phenomenon. Unfortunately, as Siris (1990) has argued, the term 'post-psychotic depression' has been used to describe three similar, but clinically distinct, groups of patients. In one group, depressive symptoms are clearly present during an acute psychotic episode and resolve as the positive psychotic symptoms resolve, although sometimes more slowly. These depressive symptoms only become apparent as the positive symptoms resolve, and the term 'revealed depression' is sometimes applied. The second definition overlaps somewhat with the first but describes patients who develop depressive symptoms as their positive psychotic symptoms resolve. The third group of patients are those in whom significant depressive symptoms appear after the acute episode has resolved. The multiplicity of terms and the different ways in which they have been used has not added to the clarity of the literature. The studies in this area have varied widely in methodology, including their definitions of significant depression.

The concept of post-schizophrenic (or postpsychotic) depression has now been incorporated into the ICD-10 (World Health Organization, 1992) classification system (and in the appendix of DSMIV; American Psychiatric Association, 1994). ICD10 offers an operationalised definition of postschizophrenic depression (Box 1) and attempts to avoid confusion by specifically stating that it is immaterial to the diagnosis whether depressive symptoms have been revealed or are a new development, and it is similarly immaterial whether depression is an intrinsic part of schizophrenia or a psychological reaction to it.

\section{Importance of depressive symptoms}

Bleuler considered prominent affective symptoms to be a good prognostic sign in schizophrenia. This notion persisted for many decades despite the lack of good evidence to support it, and evidence to the contrary is now accumulating.

Depression is an associated risk factor for death by suicide in schizophrenia. Given that $10 \%$ of patients with schizophrenia end their own lives, this is of obvious importance. Patients who kill themselves are more likely to have a history of depressive episodes and to have exhibited depressive symptoms at their last contact. Suicide in schizophrenia appears to be correlated more with hopelessness and the psychological aspects of depression than with vegetative features (Drake \& Cotton, 1986). Depression is also associated with attempted suicide (Prasad, 1986).

Cheadle et al (1978) suggested that neurotic symptoms, many of them depressive in nature, are the principal symptoms causing distress to patients with chronic schizophrenia in the community. Johnson (1981a) found that over a two-year followup period the total morbidity from depression was more than twice the duration of morbidity from acute schizophrenic symptoms and that the risk of an episode of depression was over three times the risk of an acute schizophrenic relapse. Follow-up studies have shown that depression can be the main indication for $40 \%$ of admissions (Falloon et al, 1978) and that patients who manifest post-psychotic depression are more likely to experience a psychotic relapse.

Glazer et al (1981) demonstated a link between depressive symptoms and poor performance in social roles, including difficulties in relationships with others. There also appears to be a correlation between post-psychotic depression and poor premorbid social adjustment and with insidious onset of the first psychotic episode.

\section{Cause of depression in schizophrenia}

The cause of depression, as a core symptom in schizophrenia, is not known. Interestingly, early parental loss is more common among patients with post-psychotic depression (Roy et al, 1983), as is a family history of affective disorder (Subotnik et al, 1997). Depressive symptoms are equally common in male and female patients (Addington et al, 1996). Recent work has shown an association between depressive symptoms and attentional impairment, suggesting frontal lobe dysfunction (Kohler et al, 1998a) and increased bilateral temporal lobe volumes and decreased laterality (Kohler et al, 1998b). These findings among others suggest that the neurobiology of depressive symptoms in schizophrenia may have similarities with that of depressive illness itself. Further work is required to clarify the issue.

\section{Treatment issues}

The assessment and treatment of depressive symptoms in schizophrenia remains clinically challenging. Recent advances in psychopharmacology and other treatment approaches elevate the importance of establishing the diagnosis at an early stage. The therapeutic goal is significantly to reduce 
the excess morbidity and mortality associated with depressive symptoms.

The first steps are to exclude cases of schizoaffective disorder and to treat them appropiately, to treat any medical conditions that are present,and to consider the possibility of substance misuse as a contributing factor. Any evidence that antipsychotic medication is producing akinesia should lead to a reduction in dosage and/or the introduction of anticholinergic medication. Akathisia, with its concomitant feeling of dysphoria, should always be considered in patients describing subjective mood disturbance. The akathisia/dysphoria syndrome, if present, requires active management. Use of an anticholinergic drug is generally effective. Other options include $\beta$-adrenoceptor antagonists (e.g. propranolol), a benzodiazapine or a change in antipsychotic drug.

If the above factors have been addressed and the clinician is sure that negative symptoms are not being mistaken for depressive symptoms, then the treatment options are largely dictated by the stage of the illness.

An expectant approach, with increased psychosocial support, may be the way foward if emerging depressive symptoms are thought to herald an acute relapse. Clearly, antipsychotic medication should be introduced or increased if there is serious concern that an acute episode is developing. Indeed, followup studies indicate that early intervention at the first signs of relapse improves outcome (Johnstone et al, 1984).

During acute episodes, depressive symptoms should not be treated separately from other symptoms and are likely to resolve as the episode resolves. In the majority of cases increased antipsychotic medication, increased psychosocial support and, if necessary, hospitalisation, will successfully treat depression as well as positive symptoms.

There is accumulating evidence that the new atypical antipsychotics are more efficacious in treating the depression associated with an acute episode. Olanzapine, for example, was superior to haloperidol in this regard in a recent study (Tollefson et al, 1997). Other atypicals, such as risperidone, ziprasidone and zotepine, may also have a mood-elevating effect. The atypicals may prove to be useful for the depression that emerges during the chronic phase of the illness. Clozapine has been shown to reduce hopelessness, depression and suicidality in people with chronic schizophrenia (Meltzer \& Okayli, 1995).

There is a good case for the prescription of an antidepressant when the patient has persistent depressive symptoms and is not in a phase of acute illness. There have been 11 published double-blind, placebo-controlled trials of tricyclic antidepressants. The results of these demonstrated improvement $v$. placebo in five, and no improvement in six. Unfortunately, these studies vary in patient selection criteria, particularly in relation to the patient's phase of illness, but the better-conducted trials tend to support a treatment effect (Plasky, 1991). A caveat with the tricyclics, however, is that occasionally there can be a worsening of the positive psychotic symptoms.

Clinical trials of selective serotonin reuptake inhibitors (SSRIs) have overall been in favour of an effect on depressive symptoms in schizophrenia. Some of the studies have focused more on negative symptoms and have not included patients with severe depressive symptoms. However, in general, patients seem to do better on an SSRI than with placebo. A recent study designed specifically to compare an SSRI with placebo in patients with schizophrenia with moderate or severe depression also found clear benefit (Mulholland et al, 1997). Given the relative safety of SSRIs compared with the tricyclics, they would seem to be the antidepressants of choice. However, it is necessary to bear in mind possible pharmacokinetic interactions with antipsychotics because of the enzyme inhibitory effects of some of the SSRIs on the CYP450 system.

Electroconvulsive therapy (ECT) was in earlier years often advocated for patients with schizophrenia experiencing prominent affective symptoms. This practice appears to stem from clinical observations made in the 1940s (when ECT was the only effective treatment) that patients with schizophrenia who improved with ECT often had strong affective components. However, some of these statements emanated from the USA, where many patients diagnosed as having schizophrenia would, in Europe, have received a diagnosis of affective psychosis. Chart review studies of patients given ECT in 1950, 1970 and 1985 did not find consistent evidence that patients with affective symptoms did better with ECT than others. Modern, placebocontrolled clinical trials in the 1980s did not find significant improvement in depressive symptoms in patients with schizophrenia given ECT, but did so in patients with psychotic symptoms (Cooper et al, 1995).

Rehabilitation, social support and work opportunities are likely to lessen the demoralisation seen in schizophrenia. Cognitive therapy has been shown to be effective (Kingdon et al, 1994), although its role in the treatment of depressive symptoms in particular has not been studied. Given its usefulness in treating depressive illness, this is worth exploring.

In summary, depressive symptoms in schizophrenia are common, are a significant cause of morbidity and mortality and can be adequately differentiated from other symptoms and medication effects. Such symptoms are amenable to treatment and should be actively sought out in all patients. 


\section{References}

Addington, D., Addington, J. \& Patten, S. (1996) Gender and affect in schizophrenia. Canadian Journal of Psychiatry, 41, 265-268

American Psychiatric Association (1994) Diagnostic and Statistical Manual of Mental Disorders (4th edn) (DSM-IV). Washington, DC: APA.

Cheadle, A. J., Freeman, H. L. \& Korer, J. (1978) Chronic schizophrenic patients in the community. British Journal of Psychiatry, 133, 221-227.

Cooper, S. J., Kelly, C. B. \& McClelland, R. J. (1995) Affective disorders: 3. Electroconvulsive therapy. In Seminars in Clinical Psychopharmacology (ed. D. J. King), pp. 224-258. London: Gaskell.

De Alarcon, R. \& Carney, M. W. P. (1969) Severe depressive mood changes following slow-release intra-muscular fluphenazine injection. British Medical Journal, iii, 564-567.

Drake, R. E. \& Ehrlich, J. (1985) Suicide attempts associated with akathisia. American Journal of Psychiatry, 142, 499-501.

— \& Cotton, P. G. (1986) Depression, hopelessness and suicide in chronic schizophrenia. British Journal of Psychiatry, 148, 554-559.

Falloon, I., Watt, D. C. \& Shepherd, M. (1978) A comparative controlled trial of pimozide and fluphenazine decanoate in the continuation therapy of schizophrenia. Psychological Medicine, 8, 59-70.

Glazer, W., Prusoff, B., John, K., et al (1981) Depression and social adjustment among chronic schizophrenic outpatients. Journal of Nervous and Mental Disease, 169, 712-717.

Herz, M. \& Melville, C. (1980) Relapse in schizophrenia. American Journal of Psychiatry, 137, 801-805.

Hirsch, S. R., Gaind, R., Rohde, P. D., et al (1973) Outpatient maintenance of chronic schizophrenic patients with long term fluphenazine: double-blind placebo trial. British Medical Journal, i, 633-637.

_ Jolley, A. G., Barnes, T. R. E., et al (1989) Dysphoric and depressive symptoms in chronic schizophrenia. Schizophrenia Research, 2, 259-264.

Johnson, D. A. W. (1981a) Studies of depressive symptoms in schizophrenia: I. The prevalence of depression and its possible causes; II. A two-year longitudinal study of symptoms; III. A double-blind trial of orphenadrine against placebo; IV. A double-blind trial of nortriptyline for depression in chronic schizophrenia. British Journal of Psychiatry, 139, 89-101.

- (1981b) Depressions in schizophrenia: Some observations on prevalence, aetiology and treatment. Acta Psychiatrica Scandinavica, 63 (suppl 291), 137-144.

-, Pasterski, G., Ludlow, J., et al (1983) The discontinuance of maintenance neuroleptic therapy in chronic schizophrenic patients: drug and social consequences. Acta Psychiatrica Scandinavica, 67, 339-352.

Johnstone, E. C., Owens, D. G. C., Gold, A., et al (1984) Schizophrenic patients discharged from hospital: a followup study. British Journal of Psychiatry, 145, 586-590.

King, D. J., Burke, M. \& Lucas, R. A. (1995) Antipsychotic drug-induced dysphoria. British Journal of Psychiatry, 167, 480-482

Kingdon, D., Turkington, D. \& John, C. (1994) Cognitive behaviour therapy of schizophrenia. The amenability of delusions and halucinations to reasoning. British Journal of Psychiatry, 164, 581-587.

Knights, A. \& Hirsch, S. R. (1981) 'Revealed' depression and drug treatment for schizophrenia. Archives of General Psychiatry, 38, 806-811.

Kohler, C., Gur, R. C. \& Swanson, C. L. (1998a) Depression in schizophrenia: I. Association with neuropsychological deficits. Biological Psychiatry, 43, 165-172.

_-, Swanson, C. L. \& Gur, R. C. (1998b) Depression in schizophrenia: II. MRI and PET findings. Biological Psychiatry, 43, 173-180.
Leff, J. (1990) Depressive symptoms in the course of schizophrenia. In Depression in Schizophrenia (ed. L. E. DeLisi). Washington, DC: American Psychiatric Press.

Meltzer, H. Y. \& Okalyi, G. (1995) Reduction of suicidality during clozapine treatment of neuroleptic-resistant schizophrenia: impact on risk assessment. American Journal of Psychiatry, 152, 183-190.

Mulholland, C., Lynch, G., Cooper, S. J., et al (1997) A doubleblind, placebo-controlled trial of sertraline for depressive symptoms in stable, chronic schizophrenia (abstract). Biological Psychiatry, 42, 15.

Pogue-Geile, M. (1989) Negative symptoms and depression in schizophrenia. In Depression in Schizophrenics (eds R. Williams \& J. T. Dalby), pp. 121-130. New York: Plenum.

Plasky, P. (1991) Antidepressant usage in schizophrenia. Schizophrenia Bulletin, 17, 649-657.

Prasad, A. J. (1986) Attempted suicide in hospitalised schizophrenics. Acta Psychiatrica Scandinavica, 74, 41-42.

Roy, A., Thompson, R. \& Kennedy, S. (1983) Depression in chronic schizophrenia. British Journal of Psychiatry, 142, $465-470$.

Siris, S. G. (1990) Depressive symptoms in the course of schizophrenia. In Depression in Schizophrenia (ed. L. E. DeLisi), pp. 3-23. Washington, DC: American Psychiatric Press.

- (1994) Assessment and treatment of depression in schizophrenia. Psychiatric Annals, 24, 463-467.

Subotnik, K. L., Nuechterlein, K. H., Asarnow, R. F., et al (1997) Depressive symptoms in the early course of schizophrenia: relationship to familial psychiatric illness. American Journal of Psychiatry, 154, 1551-1556.

Tollefson, G. D., Beasley, C. M., Tran, P. V., et al (1997) Olanzapine and haloperidol in the treatment of schizophrenia, schizoaffective and schizophreniform disorders: results of an international collaborative trial. American Journal of Psychiatry, 154, 457-465.

Van Putten, T., May, P. R. A. (1978) Akinetic depression in schizophrenia. Archives of General Psychiatry, 35, 11011107.

World Health Organization (1992) The ICD-10 Classification of Mental and Behavioural Disorders. Clinical Description and Diagnostic Guidelines. Geneva: WHO.

\section{Multiple choice questions}

1. Depression in schizophrenia:

a is most often seen during periods of remission

b is associated with an increased risk of attempted suicide

c may be an early sign of impending relapse

d is an insignificant cause of morbidity

e is a good prognostic sign.

2. In the differential diagnoses of depression in schizophrenia:

a alcohol misuse must be excluded

b confusion with negative symptoms sometimes occurs

c medical conditions are not important

d more consideration should be given to subjective depression

e the possibility of impending relapse should be considered. 
3. Symptoms which help to differentiate negative from depressive symptoms include:
a hopelessness
b suicidal thinking
c subjective low mood
d retardation
e anxiety.

4. Antipsychotic medication:

a frequently causes a 'pharmacogenic' depression

b may cause dysphoria without associated motor movements

c should be decreased if depressive symptoms appear in a previously stable patient

d 'akinetic' depression may account for up to $25 \%$ of cases of depressive symptoms in schizohrenia

e will often treat depressive as well positive symptoms present during acute episodes.
5. Treatments likely to be useful in the treatment of depression in schizophrenia include:

a tricyclic antidepressants

b atypical antipsychotics

c increased psychosocial support

d selective serotonin reuptake inhibitors

e hospitalisation.

\section{New from Gaskell}

\section{Psychosis: Psychological Approaches and their Effectiveness}

\section{Edited by Brian Martindale, Anthony Bateman, Michael Crowe \& Frank Margison}

There is increasing recognition by professionals and service users and planners) that psychological approaches for people with psychotic conditions can be effective, and are often much sought after by users and their families. However, these were rarely considered during the 'decade of the brain'. The book updates psychiatrists, psychologists and nurses in a range of psychological therapies that should be available in a modern mental health service. It outlines the approaches and provides or reviews evidence for their effectiveness.

The authors are expert clinicians and researchers from around the globe who describe in clear language the differing contexts, aims and methods of the treatment interventions and evidence for their effectiveness.

A wide-ranging introduction is followed by a section based on cognitive approaches, another on family, group and psychosocial approaches, followed by a psychoanalytic approach. The penultimate section describes the integration of a range of these approaches in early interventions, designed to improve the chances of full recovery in the community and minimise chronic disability. Finally, there is a comprehensive overview from Australia that gives an encouraging vision of modern mental health services for those vulnerable to severe mental disturbance and also valuable pointers to further research.

May 2000, £25.00, paperback, ISBN 1901242498

Booksales, Royal College of Psychiatrists, 17 Belgrave Square, London SW1X 8PG. Tel: +44 (0)20 72352351 ext.146; Fax: +44 (0)20 72451231

The latest information on College publications is on the Internet at http://www.rcpsych.ac.uk 